\title{
Arsenic removal from soil with high iron content using a natural surfactant and phosphate
}

\author{
S. Mukhopadhyay • M. A. Hashim • \\ M. Allen • B. Sen Gupta
}

Received: 19 November 2012/Revised: 16 May 2013/Accepted: 17 November 2013/Published online: 10 December 2013

(C) Islamic Azad University (IAU) 2013

\begin{abstract}
An environment friendly arsenic removal technique from contaminated soil with high iron content has been studied. A natural surfactant extracted from soapnut fruit, phosphate solution and their mixture was used separately as extractants. The mixture was most effective in desorbing arsenic, attaining above $70 \%$ efficiency in the $\mathrm{pH}$ range of 4-5. Desorption kinetics followed Elovich model. Micellar solubilization by soapnut and arsenic exchange mechanism by phosphate are the probable mechanisms behind arsenic desorption. Sequential extraction reveals that the mixed soapnut-phosphate system is effective in desorbing arsenic associated with amphoteric-Fe-oxide forms. No chemical change to the wash solutions was observed by Fourier transform-infrared spectra. Soil:solution ratio, surfactant and phosphate concentrations were found to affect the arsenic desorption process. Addition of phosphate boosted the performance of soapnut solution considerably. Response surface methodology approach predicted up to $80 \%$ desorption of arsenic from soil when treated with a mixture of $\approx 1.5 \%$ soapnut, $\approx 100 \mathrm{mM}$ phosphate at a soil:solution ratio of $1: 30$.
\end{abstract}

Keywords Soil washing · Soapnut · Phosphate . Sapindus mukorossi · Arsenic

S. Mukhopadhyay · M. A. Hashim ( $₫)$

Department of Chemical Engineering, University of Malaya,

50603 Kuala Lumpur, Malaysia

e-mail: alihashim@um.edu.my

M. Allen · B. Sen Gupta

School of Planning, Architecture and Civil Engineering, Queen's

University, Belfast BT9 5AG, UK

\section{Introduction}

Arsenic (As) is an extremely toxic metalloid and has been studied extensively for its hazardous nature (Jain and Ali 2000; Jomova et al. 2011). Unsafe irrigation and industrial practices may cause accumulation of in soil posing serious health risk. Moreover, mining, smelting, coal burning, wood preservation and illegal waste dumping activities result in arsenic pollution in the environment (Tokunaga and Hakuta 2002). Arsenic is non-biodegradable, and its mobility depends upon various geochemical processes (Cheng et al. 2009; Craw 2005), exposing human beings to its toxic effects including cancer, cardiovascular disease, neurological disorders and gastrointestinal disturbances (Jomova et al. 2011). In the past, arsenic-contaminated soils were treated using various technologies (Wang and Zhao 2009; Mulligan et al. 2001b). Among these techniques, soil washing using alkaline reagents, organic and inorganic acids, phosphates, biosurfactants and Bureau of Reference (BCR) extraction procedures proved viable (Alam et al. 2001; Jang et al. 2005; Tokunaga and Hakuta 2002; Chen et al. 2008; Mulligan and Wang 2006; Wang and Mulligan 2009). The effectiveness of these reagents in extracting arsenic depends upon the arsenic speciation in soil (Lee and Kao 2004). In this work, a natural surfactant obtained from Sapindus mukorossi, in conjunction with phosphate solution, is used to remove arsenic from an artificially contaminated soil matrix.

Saponin is a plant-based surfactant effective for metal desorption from soil (Chen et al. 2008; Song et al. 2008). In this work, saponin was obtained from the fruit pericarp of Sapindus mukorossi or soapnut. Soapnut tree is common in Indo-Gangetic plains, Shivaliks and sub-Himalayan tracts. The fruit pericarp contains a natural surfactant triterpenoidal saponin that has been used as detergent and 
medicine for many decades (Suhagia et al. 2011). These triterpenoidal saponins are of mainly three types: viz oleanane, dammarane and tirucallane type (Suhagia et al. 2011). Saxena et al. (2004) isolated six different saponins from the fruits of Sapindus mukorossi, viz. Sapindoside A, Sapindoside B, Sapindoside C, Sapindoside D, Mukorozisaponin E1 and Mukorozisaponin Y1 by LC-MS and also described their molecular structures. Previously, Roy et al. (1997) and Kommalapati et al. (1997) used soapnut solution for removing hexachlorobenzene and organic pollutants from soil through micellar solubilization and reduced interfacial tension between contaminant and solution (Kommalapati et al. 1997; Roy et al. 1997). However, soapnut has never been used for metal/metalloid removal from soil. Soapnut is completely benign for environment, biodegradable and thus safe for both ex situ and in situ soil washing process (Kommalapati and Roy 1996). It is supposed to be a better alternative for synthetic inorganic surfactants, which are not biodegradable and may have some unwanted environmental impact.

Phosphate has long been used for removing arsenic from soil due to its ability $\left(\mathrm{PO}_{4}{ }^{3-}\right)$ to replace arsenic or arsenate $\left(\mathrm{AsO}_{4}{ }^{3-}\right)$. Alam et al. (2001) extracted up to $40 \%$ arsenic from a forest soil by $0.9 \mathrm{M}$ phosphate solution (Alam et al. 2001). Wasay et al. (2000) removed $80 \%$ of the bound arsenic by phosphate from a contaminated loamy soil in the pH range of 5 to 7 at $20^{\circ} \mathrm{C}$ (Wasay et al. 2000). Tokunaga and Hakuta (2002) also extracted $99.9 \%$ of arsenic from an artificially contaminated soil with $9.4 \%$ phosphoric acid solution. Zeng et al. (2008) used $\mathrm{H}_{3} \mathrm{PO}_{4}$ and $\mathrm{KH}_{2} \mathrm{PO}_{4}$ to desorb arsenic from soil and attained more than $20 \%$ arsenic removal at a concentration of $200 \mathrm{mM} / \mathrm{L}$ of phosphate. Although $\mathrm{KH}_{2} \mathrm{PO}_{4}$ and $\mathrm{H}_{3} \mathrm{PO}_{4}$ achieved similar results, $\mathrm{KH}_{2} \mathrm{PO}_{4}$ did less damage to soil and was found to be more environment friendly. Hence, in this work, $\mathrm{KH}_{2} \mathrm{PO}_{4}$ was combined with soapnut to desorb arsenic from soil. However, Zeng et al. (2008) experienced acidity of soil at higher concentration of this salt. Consequently, we used much lower concentration, in the range of $50-150 \mathrm{mM}$. Also, phosphate is used in the agricultural fields in the form of NPK fertilizers. Therefore, phosphate will always be present in such soils and will interact with soapnut even if the later is used singularly in the fields. Response surface method was used to determine the optimum ratio of soapnut and phosphate for arsenic removal (Zeng et al. 2008).

Although both $\mathrm{As}(\mathrm{V})$ and $\mathrm{As}(\mathrm{III})$ compounds are available in natural conditions, $\mathrm{As}(\mathrm{V})$ salt was used in this study as the $\mathrm{pH}$ and redox values in the sampling site favoured the presence of $\mathrm{As}(\mathrm{V})$ over As(III) (Dobran and Zagury 2006; Smedley and Kinniburgh 2002). Speciation in contaminated soil was confirmed by a solvent extraction process. Moreover, compared with $\mathrm{As}(\mathrm{III}), \mathrm{As}(\mathrm{V})$ is more difficult to remove from $\mathrm{Fe}(\mathrm{III})$-bearing minerals of soil components and usually the soils retain arsenic in its +5 state (Yamaguchi et al. 2011).

In this work, arsenic removal has been attempted at lower levels of an order of magnitude matching that of irrigated paddy field rather than that of mine tailings. The pollutant removal becomes difficult at lower concentrations (Sundstrom et al. 1989). Moreover, the soil sample used in this work contains maghemite, which has a high affinity for As(V) (Chowdhury and Yanful 2010). Soapnut solution, phosphate solution and their combinations were compared with an anionic synthetic surfactant sodium dodecyl sulphate (SDS; $\mathrm{NaCl}_{2} \mathrm{H}_{25} \mathrm{SO}_{4}$ ), widely used for soil washing and metal removal (Kommalapati et al. 1997; Roy et al. 1995). The objectives of this research were to study: (1) effect of phosphate on the performance of soapnut solution in $\mathrm{As}(\mathrm{V})$ removal from soil; (2) effect of various operational factors such as soil:solution ratio, surfactant concentration and phosphate concentration on the soil washing process; and (3) determination of composition of soapnutphosphate mixture for achieving optimum $\mathrm{As}(\mathrm{V})$ removal performance. The research was being carried out in Kuala Lumpur, Malaysia, at room temperature of $25^{\circ} \mathrm{C}$ during the months of August and September 2012.

\section{Materials and methods}

Soil sample, surfactants and analytical methods

A composite soil sample was obtained from the second layer aquifer in Hulu Langat area, Selangor, Malaysia. The soil was dried in an oven overnight at $105^{\circ} \mathrm{C}$, crushed and passed through a 2-mm sieve following the protocol presented by Roy et al. (1997). It was classified according to USDA soil texture triangle. XRD analysis was performed by a Panalytical Empyrean diffractometer using Highscore Plus software. The soil $\mathrm{pH}$ was measured by USEPA SW846 Method 9045D, while Eh was measured by an ORP electrode following ASTM Method D 1498-93 after preparing the sample by USEPA Method 9045 for soil samples as suggested in SW-846 series. As(V) salt $\left(\mathrm{Na}_{2} \mathrm{HA}\right.$ $\mathrm{sO}_{4} \cdot 7 \mathrm{H}_{2} \mathrm{O}$ ) was used for spiking the soil matrix depending on the Eh and $\mathrm{pH}$ of the unspiked soils (Tokunaga and Hakuta 2002). The soil was spiked by $200 \mathrm{mg} \mathrm{L}^{-1}$ concentrations of sodium arsenate solution, at room temperature by mixing it for 7 days at weight: volume ratio of 3:2. The As-spiked soil sample was washed with 2 pore volumes of artificial rainwater of $\mathrm{pH} 5.9$ consisting of $\left.5 \times 10^{-4} \mathrm{M} \mathrm{Ca} \mathrm{NO}_{3}\right)_{2}, 5 \times 10^{-4} \mathrm{M} \mathrm{CaCl}_{2}, 5 \times 10^{-4} \mathrm{M}$ $\mathrm{MgCl}_{2}, 10^{-4} \mathrm{M} \mathrm{KCl}$ and $10^{-4} \mathrm{M} \mathrm{Na}_{2} \mathrm{SO}_{4}$ following the method proposed by Oorts et al. (2007) to increase the field relevance, and thereafter, it was equilibrated overnight. 
Table 1 Characterization of extractants and soil

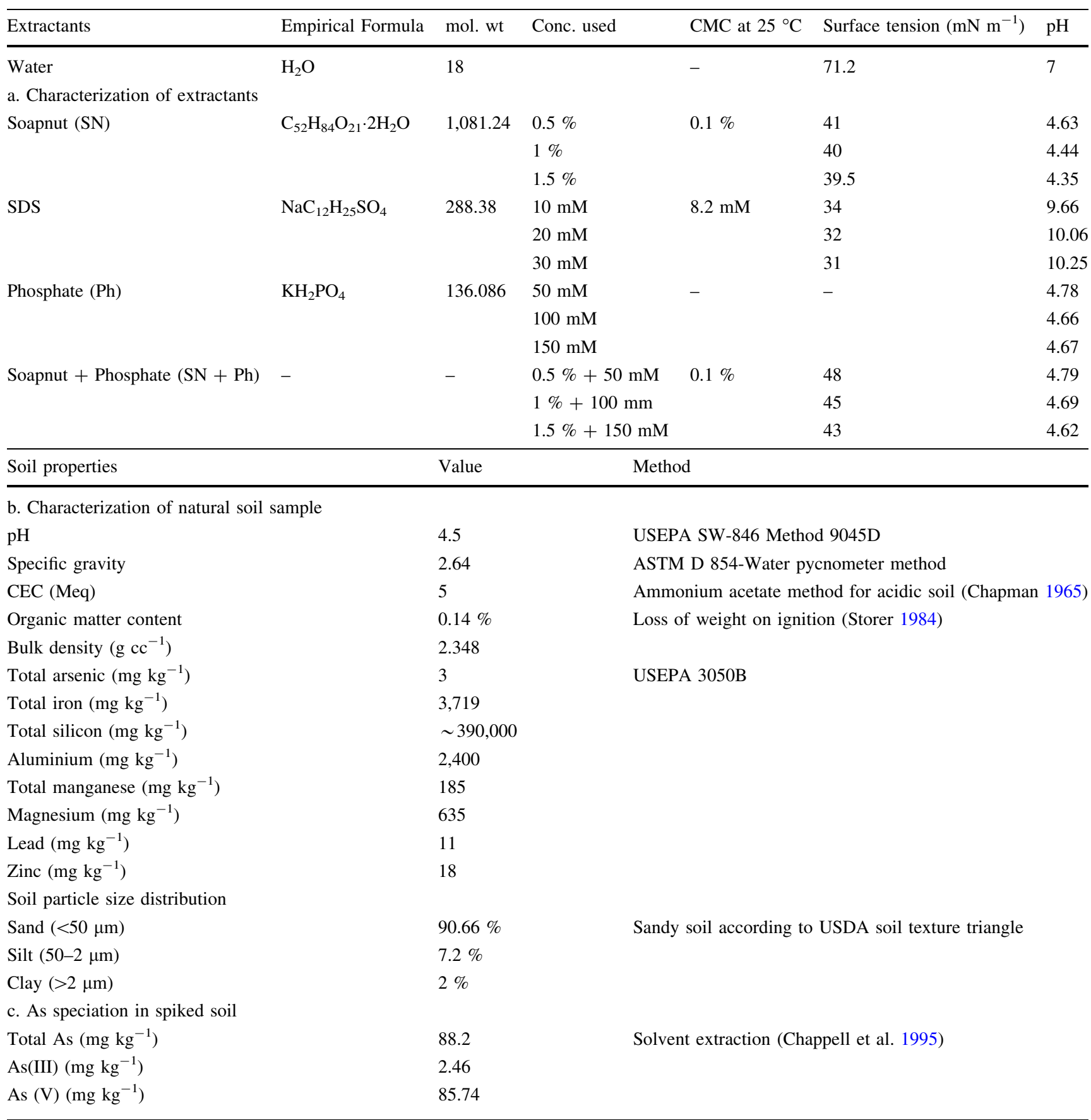

After that, the soils were allowed to drain overnight and then air dried at $25{ }^{\circ} \mathrm{C}$ for $24 \mathrm{~h}$ and sieved through 2-mm mesh. They were digested following USEPA Method 3050B to measure metal contents by ICP-OES (PerkinElmer Optima 7000DV) using Perkin-Elmer multimetal standard solutions. All the samples were analyzed in triplicate, and the results were reproducible within $\pm 3.5 \%$. Based on some preliminary experiments, $10-30 \mathrm{mM}$ of SDS, $0.5-1.5 \%$ (w/w) of Sapindus mukorossi (soapnut) extractions and 50-150 mM phosphate solution (prepared from $\mathrm{KH}_{2} \mathrm{PO}_{4}$ ) were used for the $\mathrm{As}(\mathrm{V})$ desorption from the soil and were compared with water blank. The used surfactant concentrations were well above their CMC.

The characteristics of these extractants are described in Table 1a. The plant-based surfactant saponin was extracted from the soapnut fruit pericarp by water as described by Roy et al. (1997). The surface tension and critical micelle concentration (CMC) of surfactants were measured by a ring-type surface tensiometer (Fisher Scientific Manual Model 20 Surface Tensiometer). The functional groups 
Table 2 Experimental conditions and variables

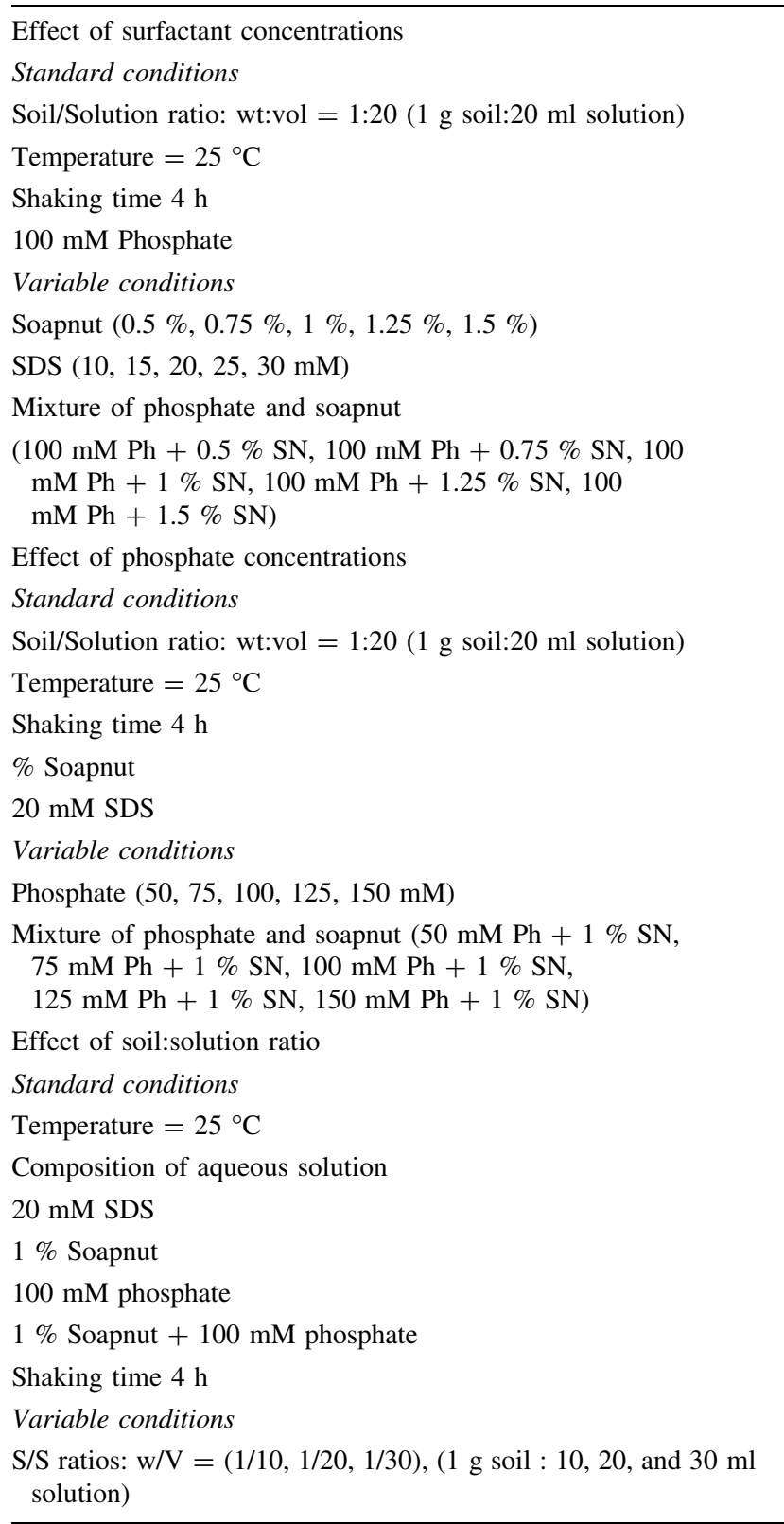

present in the soapnut extract and the effluent solution were characterized by FT-IR spectroscopy (PerkinElmer Spectrum 100 Series FT-IR spectrometers), and the transmittance spectra were plotted using a built-in plotter. IR spectra were recorded in the range of 400-4,000 wave numbers $\left(\mathrm{cm}^{-1}\right)$.

Kinetic study for $\mathrm{As}(\mathrm{V})$ desorption

Methods suggested by Tokunaga and Hakuta (2002) were used to conduct kinetic study experiments. Four soil samples of 10 gram were shaken with $200 \mathrm{ml}$ of four solutions viz $1 \%$ soapnut, $20 \mathrm{mM}$ SDS, $100 \mathrm{mM}$ phosphate and
$1 \%$ soapnut $+100 \mathrm{mM}$ phosphate in $500-\mathrm{ml}$ conicals at $135 \mathrm{rpm}$ at a controlled temperature of $25^{\circ} \mathrm{C}$. $\mathrm{pH}$ values were recorded, and 5-ml samples were filtered and collected at intervals of $5,10,15,20,25,30,45,60,120 \mathrm{~min}$ and 4, 6, 21, 24 and $48 \mathrm{~h}$. The samples were double diluted and stored for ICP-OES analysis after adding 1 drop of $\mathrm{HNO}_{3}$. The kinetic data were fitted by first-order, parabolic diffusion, Elovich, and power function models in order to examine the arsenic desorption mechanism. The best fit model was determined by the values of determination coefficients and standard errors.

Batch experiments for effects of surfactant concentration, phosphate concentration and soil:solution ratio

In order to investigate the effects of surfactant and phosphate concentration and soil:solution ratio on the arsenic extraction process, batch tests were conducted in $100-\mathrm{ml}$ conical flasks following Jang et al. (2005), with minor modifications. The flasks were shaken for $4 \mathrm{~h}$ at $25{ }^{\circ} \mathrm{C}$. The variables and conditions for the experiments are listed in Table 2 .

\section{Zeta potential measurement}

For zeta potential measurement, five $20-\mathrm{ml}$ solutions were prepared viz, $1 \%$ soapnut, $20 \mathrm{mM}$ SDS, $100 \mathrm{mM}$ phosphate, $1 \%$ soapnut $+100 \mathrm{mM}$ phosphate and distilled water as blank. Approximately $0.05 \mathrm{~g}$ of the contaminated sediment was added to these solutions before measurement to enable tracking since a higher concentration interferes with the particles and reduces the tracking rate (Mulligan et al. 2001a).

\section{Sequential extraction for soil fractionation}

Mihaljevič et al. (2005) analyzed that Hall's method of sequential extraction of arsenic from mixture of minerals such as As-bearing goethite, calcium arsenate and arsenopyrite was superior than some other extraction methods which failed to quantitatively oxidize the arsenopyrite (Mihaljevič et al. 2003). Therefore, in this work, Hall's extraction method was used (Hall et al. 1996).

\section{Damage to soil}

Change in soil $\mathrm{pH}$ was noted while doing the kinetic study over a period of $48 \mathrm{~h}$. Some selected samples from batch experiments described in "Batch experiments for effects of surfactant concentration, phosphate concentration and soil:solution ratio" section were analyzed for $\mathrm{Ca}, \mathrm{Mg}, \mathrm{Si}$, 


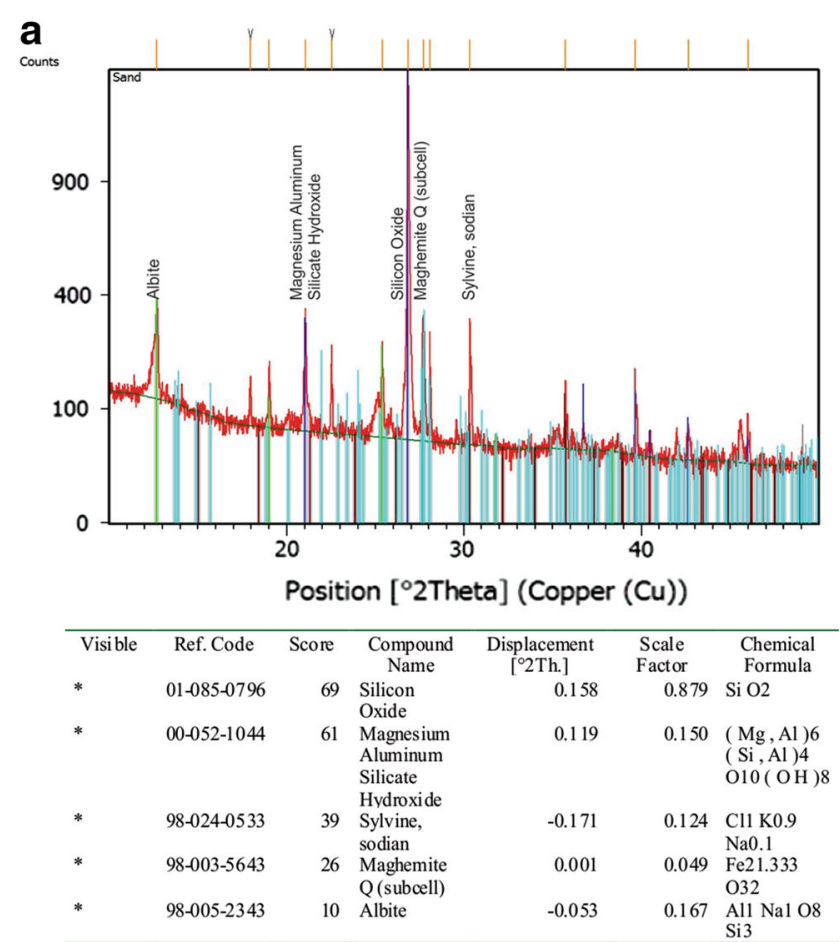

Fig. 1 a XRD spectra of the As(V) spiked soil sample, b initial and final $\mathrm{pH}$ and Eh values of contaminated soil during column washing experiment reported in the Eh-pH diagram for the system As-O-H at

$\mathrm{Fe}, \mathrm{Al}$ to check for any structural damage of soil following Zeng et al. (2008).

Design of experiments by Box-Behnken design

A Box-Behnken (BB) experimental design having 3 factors and 3 levels was selected for investigating the effects of selected variables. BB designs are a type of response surface methods (RSM) requiring 3 levels of parameters, coded as $-1,0$, and +1 . The range of experimental design matrix is shown in Table 2. The observed data were fitted to a second-order polynomial model, which are discussed in "Mechanism, fractionation and soil damage" section. Response is recorded in terms of percentage of arsenic removal from the soil, defined by the Eq. 1 .

As removal $(\%)=\frac{[\mathrm{As}]_{\mathrm{wash}} \times V \times 100}{1000 \times \mathrm{As}_{\text {soil }}}$

where $[\mathrm{As}]_{\text {wash }}$ is the concentration of arsenic in the wash liquid, or simply the data obtained from ICP-OES in $\mathrm{mg} \mathrm{L}^{-1}, \mathrm{As}_{\text {soil }}$ is the total amount of arsenic (in $\mathrm{mg}$ ) in the $1 \mathrm{~g}$ of soil used for the experiment, $V$ is the volume of wash liquid used.

The results were analyzed by Design Expert 7.0 software, and the interactions of different factors were determined. Since the responses varied from 48.837 to 79.558 , the ratio of maximum to minimum is 1.629 . A ratio above b

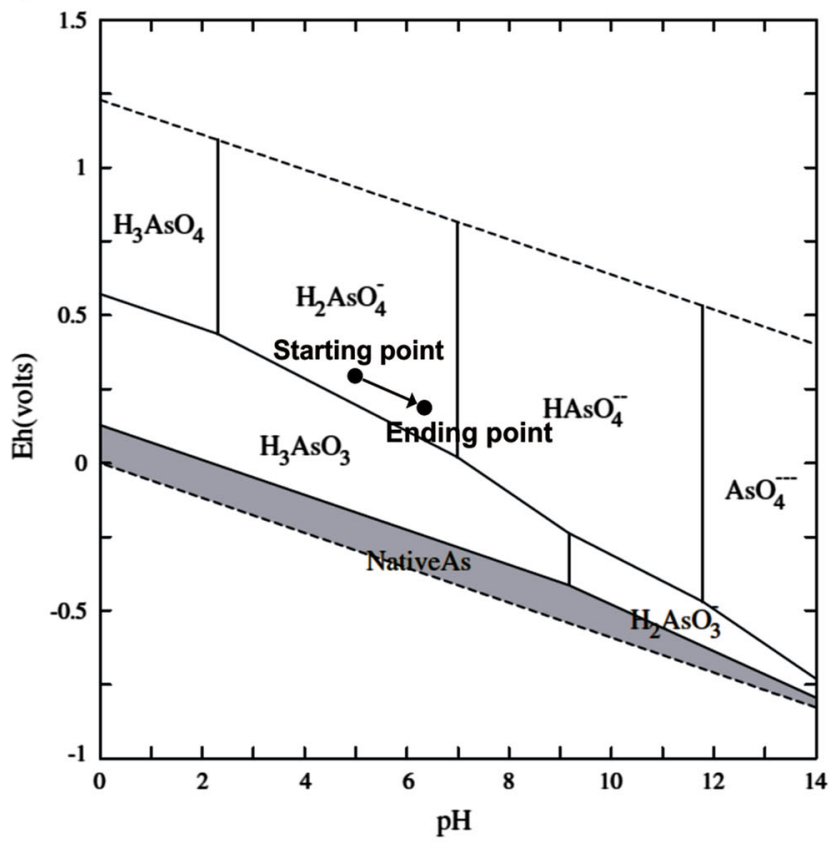

$25^{\circ} \mathrm{C}$ and 1 bar with activities of soluble As species $=10^{-6} \mathrm{M}$. The revised $\mathrm{Eh}-\mathrm{pH}$ diagram is taken from $\mathrm{Lu}$ and $\mathrm{Zhu}$ (Lu and $\mathrm{Zhu} 2011$ ). Gray-shaded areas denote solid phases

10 usually indicates the necessity of a transformation on the datasets. Therefore, in this case, no transformation was applied on the data and the 2FI model was investigated. Regression analysis was performed, and response surfaces were obtained for finding the most desirable combination of control factors resulting in maximum $\mathrm{As}(\mathrm{V})$ desorption. The statistical significance of variables was evaluated using the ANOVA and Student's $t$ test. Adequacy of the constructed models is investigated via lack of fit, coefficient of determination $\left(R^{2}\right)$ and $F$ values.

\section{Results and discussion}

\section{Soil characterization}

The soil was found to be sandy in texture following USDA soil texture triangle (Table 1a). XRD analysis of both spiked and unspiked soils revealed that the soil samples contained Silicon Dioxide as quartz $\left(\mathrm{SiO}_{2}\right)$, Magnesium Aluminum Silicate Hydroxide as mica $((\mathrm{Mg}$, $\left.\mathrm{Al})_{6}(\mathrm{Si}, \mathrm{Al})_{4} \mathrm{O}_{10}(\mathrm{OH})_{8}\right)$, Sylvine, sodian $\left(\mathrm{Cl}_{1} \mathrm{~K}_{0.9} \mathrm{Na}_{0.1}\right)$, Maghemite Q (Isometric $\mathrm{Fe}_{21.33} \quad \mathrm{O}_{32}$ ), and feldspar Albite $\left(\mathrm{Al} \mathrm{Na} \mathrm{O}_{8} \mathrm{Si}_{3}\right)$. The XRD spectrum of the spiked soil is shown in Fig. 1a. Arsenic was not detected in the mineral phase as expected in such low levels as $88.2 \mathrm{mg} \mathrm{kg}^{-1}$. 
Arsenic sorption in soil and its speciation

The soil spiked with $200 \mathrm{mg} \mathrm{L}^{-1}$ arsenic solution retained $88.2 \mathrm{mg} \mathrm{kg}^{-1}$ of arsenic after washing with artificial rain water of pH 5.9. According to Jacobs et al. (1970), arsenic is retained in the soil matrix mostly by hydrous oxides of $\mathrm{Fe}(\mathrm{III})$ and $\mathrm{Al}(\mathrm{III})$. The presence of these minerals in the soil sample is confirmed by XRD spectra and ICP-OES data. Arsenic adsorption by soil organic matter and silica are negligible (Wasay et al. 1996; Weng et al. 1997). The unspiked soil had a $\mathrm{pH}$ value of 4.5 and $\mathrm{Eh}$ value of about $270 \mathrm{mV}$. According to the revised $\mathrm{Eh}-\mathrm{pH}$ diagrams for the As-O-H system at $25{ }^{\circ} \mathrm{C}$ and 1 bar by Lu and Zhu (2011), arsenic is expected to exist in +5 state under these conditions in aqueous matrices. Hence, aqueous solution of $\mathrm{Na}_{2} \mathrm{HAsO}_{4} \cdot 7 \mathrm{H}_{2} \mathrm{O}$ was used to spike the soil. Even after spiking and washing the soil, the $\mathrm{pH}$ and $\mathrm{Eh}$ values of soil were found to be 6.60 and $205 \mathrm{mV}$, respectively. This scenario is described in the $\mathrm{Eh}-\mathrm{pH}$ diagram by pointing out the initial and final $\mathrm{Eh}$ and $\mathrm{pH}$ of the unspiked and spiked soil in Fig. 1b. A slight drop in Eh value of the spiked soil was accompanied by an increase in soil $\mathrm{pH}$ value.

The arsenic speciation in high- and low-contaminated soils by solvent extraction confirmed the presence of As(V) species (up to $94 \%$ of total arsenic), and the data are given in Table 1c.

Extraction of arsenic from soil by different extractants

As(V) desorption experiments were performed with SDS, soapnut, phosphate and soapnut + phosphate solutions at concentrations as shown in Fig. 2. The figure compares the overall performance of the extractants at one of the intermediate concentrations used along with the resulting $\mathrm{pH}$ when different extractants were added with the soil at a wt:vol ratio of 1:20.

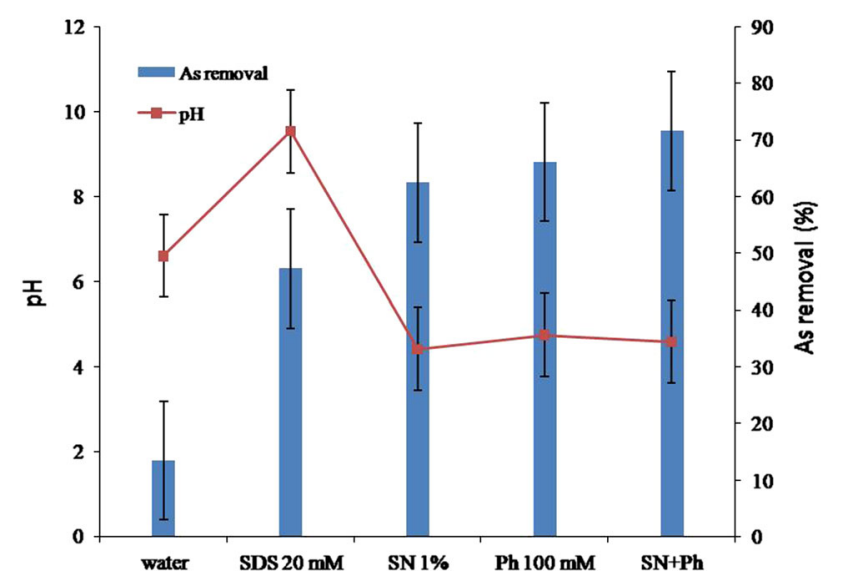

Fig. 2 Performance of different extractants for arsenic removal from soil (Error bars with standard error are included)
Significant As(V) removal was obtained by $1 \%$ soapnut, $100 \mathrm{mM}$ phosphate and $1 \%$ soapnut $+100 \mathrm{mM}$ phosphate solutions in increasing order of magnitude. However, SDS, though anionic, is not as effective as other washing agents used in the study. $\mathrm{pH}$ of the extractants was found to have negative correlation with the desorption of As(V); more acidic the solution, more As(V) desorbed. SDS, being highly alkaline, could not extract comparable amount of $\mathrm{As}(\mathrm{V})$. The acidic soil, whose $\mathrm{pH}$ is 4.5 , may have caused SDS precipitation. Distilled water, used as a control, removes only $13.45 \% \mathrm{As}(\mathrm{V})$. In comparison with water, SDS $20 \mathrm{mM}$ removes 3.5 times more As(V), $1 \%$ soapnut removes 4.6 times, $100 \mathrm{mM}$ phosphate removes $4.9 \%$ and solution of $1 \%$ soapnut and $100 \mathrm{mM}$ phosphate removes 5.3 times compared with water on its own. Therefore, water is not effective enough to desorb As $(V)$ from the soil. This is justified by the presence of large amount of $\mathrm{Fe}(\mathrm{III})$ in the soil which binds the As(V). The proportion of As(III) is very negligible in the soil, as evident from Table 1c.

Kinetic properties for As(V) desorption from soil

\section{Equilibrium time}

The experimental results of $\mathrm{As}(\mathrm{V})$ desorption are shown in Fig. 3a where the concentration of the As(V) in the extractants at different times have been plotted. Although experiments were continued for 48 h, Fig. 3a shows results up to $6 \mathrm{~h}$ although the equilibrium was attained within $4 \mathrm{~h}$. There was a plateau region during the time period of 10-30 min, after which the desorption increased once again to get stabilized at $4 \mathrm{~h}$. In order to achieve maximum desorption and investigate the corrosive effect of soapnut on the soil, we have used the longer 4-h period for all other experiments. The decreasing order of desorption amounts in $4 \mathrm{~h}$ were $\mathrm{SN}+\mathrm{Ph}>\mathrm{SN}>$ Phosphate $>\mathrm{SDS}$. The curves are fitted in logarithmic equations, and the $R^{2}$ values are mostly above 0.90 , as illustrated in the Fig. 3a.

\section{Desorption rate of $A s(V)$}

Desorption rate of $\mathrm{As}(\mathrm{V})$ was defined as the amount of As desorbed from unit mass of soil $(q)$ per unit time ( $\mathrm{Li}$ et al. 2001). It can be mathematically expressed as in Eq. 2:

$V(\mathrm{mg} / \mathrm{min})=q(\mathrm{mg}) / t(\min )$

The experimental data showed that $\mathrm{As}(\mathrm{V})$ desorption rates were almost similar for all the extractants. Longer desorption time to reach the equilibrium signifies lower desorption rate. The desorption rate $(V)$ for different reaction phases is described using the two-constant rate equation following $\mathrm{Li}$ et al. (2001) as in Eq. 3 . 

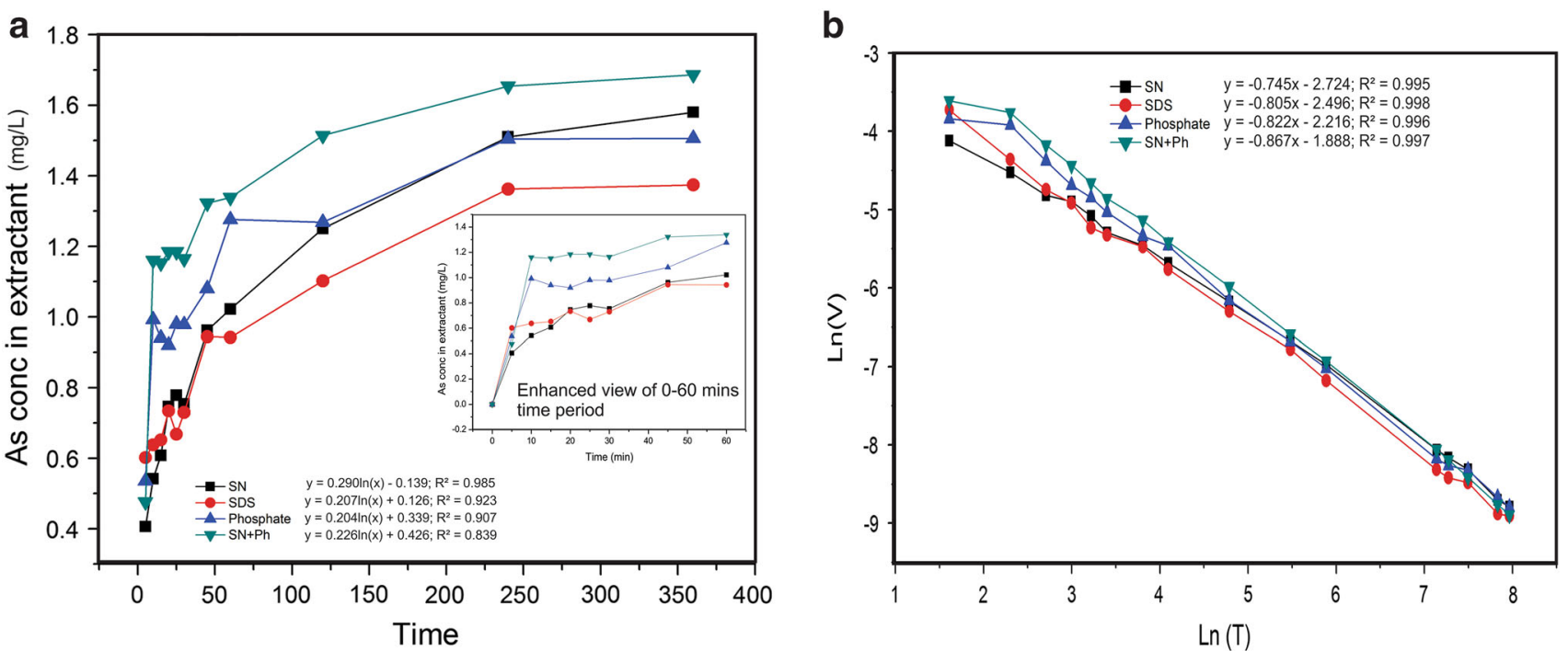

Fig. 3 a Kinetics of $\mathrm{As}(\mathrm{V})$ desorption from contaminated soil, enhanced view of 0-60 min is shown in inset $\mathbf{b}$ relation between $\ln V$ and $\ln t$ with different extractants for As desorption

$\ln V=A+B \ln t$

where $A$ and $B$ are constants. $B$ is the indicator of change in $\operatorname{As}(\mathrm{V})$ desorption rate. Lower value of $B$ signifies faster drop in desorption rate. As shown in Fig. $3 b, \ln (V)$ is linearly correlated with $\ln (t)$ to obtain the $\mathrm{B}$ and $\mathrm{R}^{2}$ values for SDS (-0.805, 0.998), SN (-0.745, 0.995), Phosphate $(-0.822,0.996)$ and $\mathrm{SN}+\mathrm{Ph}(-0.867,0.997)$.

\section{The kinetic models of $A s(V)$ desorption}

A number of models had previously been used for describing adsorption and desorption phenomena of metal ions on soils. Carski and Sparks (1987) explained desorption of ammonium ions from soils by a first-order kinetic model. Sparks et al. (1980a) modified the Freundlich model for studying the kinetics of potassium adsorption on soils (Sparks et al. 1980a, b). The parabolic diffusion model was used to describe diffusion-controlled phenomena in soil and the release of ions in soils (Havlin et al. 1985). The Elovich model has been used for same purpose (Chien and Clayton 1980). These four models are stated in Eqs. 4-7 (Li et al. 2001):

Elovich equation: $S=A+B \ln t$

Parabolic diffusion equation: $S / S_{\max }=A+B t^{1 / 2}$

Two - constant rate equation: $\ln S=A+B \ln t$

First - order kinetic equation: $\ln \left(S_{0}-S\right)=A+B t$

where $S=$ amount of As desorbed at any time, $S_{\max }=$ maximum amount of As $(\mathrm{V})$ desorbed from the soil, $t=$ time, $A$ and $B=$ parameters of the equations. For easier understanding, all of the original constants in the four models have been replaced by $A$ or $B$.
The fit between the kinetic models and the amounts of $\mathrm{As}(\mathrm{V})$ desorbed on the soils have been presented in Table 3. As the value of $R^{2}$ increases, the value of $\mathrm{SE}$ decreases, indicating a better representation of the model. When overall means are calculated for all the extractants, then the best model of $\mathrm{As}(\mathrm{V})$ desorption from soil is the Elovich equation with $R^{2}$ and SE values of 0.969 and 0.017 , respectively. Even if the models for all the extractants are inspected separately, the Elovich equation emerges as the best model for all the extractants for desorbing $\mathrm{As}(\mathrm{V})$ from this particular sandy soil.

\section{Effect of phosphate concentration}

As $(\mathrm{V})$-contaminated soil is treated with different concentrations of phosphate solutions (initial $\mathrm{pH}$ 4.67-4.78). The concentration is gradually varied from 50 to $150 \mathrm{mM}$ keeping in mind that excess phosphate in agricultural field may run-off to the water bodies, producing algal boom. Although Alam et al. (2001) observed good arsenic removal at $300 \mathrm{mM}$ phosphate concentration, the present work uses even less amount of phosphate both for economic reasons and environmental sustainability issues. As shown in Fig. 4a, only $13.45 \% \mathrm{As}(\mathrm{V})$ is removed by water. In comparison, $50 \mathrm{mM}$ phosphate solution removes $56.14 \% \mathrm{As}(\mathrm{V})$ and this amount increases till $100 \mathrm{mM}$, after which the increment is insignificant. However, the effect of phosphate is not significant for $1 \%$ soapnut and phosphate mixtures. The $\mathrm{As}(\mathrm{V})$ extraction is much higher than only phosphate and stays in the range of $69-71 \%$. Thus, in case of a mixed extractant, the role of phosphate is found to be of secondary in importance. For all other experiments, $100 \mathrm{mM}$ phosphate solutions are used. 
Table 3 Correlation coefficients $R^{2}$ and standard error (SE) of four kinetic models

\begin{tabular}{|c|c|c|c|c|c|c|c|c|}
\hline & \multicolumn{4}{|c|}{ Two-constant rate equation } & \multicolumn{4}{|c|}{ Elovich equation } \\
\hline & \multicolumn{4}{|c|}{$\ln S=A+B \ln t$} & \multicolumn{4}{|c|}{$S=A+B \ln t$} \\
\hline & $A$ & $B$ & $R^{2}$ & SE & $A$ & $B$ & $R^{2}$ & SE \\
\hline SN & -2.962 & 0.327 & 0.985 & 0.108271 & -0.034 & 0.060 & 0.991 & 0.012613 \\
\hline SDS & -2.588 & 0.222 & 0.940 & 0.078728 & 0.017 & 0.043 & 0.965 & 0.018498 \\
\hline Phosphate & -2.310 & 0.206 & 0.847 & 0.109404 & 0.047 & 0.047 & 0.961 & 0.020983 \\
\hline $\mathrm{SN}+\mathrm{Ph}$ & -2.027 & 0.174 & 0.829 & 0.106551 & 0.117 & 0.037 & 0.959 & 0.017301 \\
\hline \multirow[t]{4}{*}{ Mean } & & & 0.900 & 0.101 & & & 0.969 & 0.017 \\
\hline & \multicolumn{4}{|c|}{ Parabolic diffusion equation } & \multicolumn{4}{|c|}{ First-order kinetics } \\
\hline & \multicolumn{4}{|c|}{$S / S_{\max }=A+B \mathrm{t}^{1 / 2}$} & \multicolumn{4}{|c|}{$\ln \left(S_{0}-S\right)=A+B \mathrm{t}$} \\
\hline & $A$ & $B$ & $R^{2}$ & SE & $A$ & $B$ & $R^{2}$ & SE \\
\hline SN & 0.302 & 0.015 & 0.888 & 0.102688 & -0.342 & $-1.00 \mathrm{E}-04$ & 0.753 & 0.118103 \\
\hline SDS & 0.349 & 0.012 & 0.911 & 0.075843 & -0.324 & $-1.00 \mathrm{E}-04$ & 0.762 & 0.083618 \\
\hline Phosphate & 0.403 & 0.012 & 0.908 & 0.074692 & -0.380 & $-1.00 \mathrm{E}-04$ & 0.766 & 0.099029 \\
\hline $\mathrm{SN}+\mathrm{Ph}$ & 0.567 & 0.010 & 0.799 & 0.09695 & -0.441 & $-1.00 \mathrm{E}-04$ & 0.560 & 0.117836 \\
\hline Mean & & & 0.877 & 0.088 & & & 0.710 & 0.105 \\
\hline
\end{tabular}

Effect of surfactant concentration

Surfactants such as soapnut and SDS have been used along with phosphate solution to extract $\mathrm{As}(\mathrm{V})$ from soil. Soil washing with different surfactant concentrations is shown in Fig. 4b. For mixed phosphate and soapnut system, the phosphate concentration is fixed at $100 \mathrm{mM}$ and soapnut concentration is varied. As expected, the extraction efficiency is found to increase with surfactant concentration due to the increasing number of micelle in higher surfactant concentration, facilitating the micellar solubilization of the pollutant from the surface of the soil particles (Mulligan 2005; Mulligan et al. 1999). The arsenic desorption from the lowest to highest concentration of soapnut are 51.88, 53.47, 54.54, 56.2 and $57.7 \%$. The corresponding values for SDS are much lower viz., 38.5, 41.78, 44.2, 46.77, and 47.2\%, respectively. Soapnut-phosphate mixture has much more higher desorption, increasing with concentration of the extractant solution viz., 58.24, 63.77, 70.62, 72.98 and $74.43 \%$ (Fig. 4bI).

The final $\mathrm{pH}$ values were measured after $4 \mathrm{~h}$ of reaction time and are presented in Fig. 4bII. In case of soapnut and soapnut-phosphate mixture, the solutions became more acidic with increasing concentration. It was observed that the increasing acidity desorbed more $\mathrm{As}(\mathrm{V})$ from soil at higher concentrations. The $\mathrm{pH}$ of soapnut decreases from 4.73 at $0.5 \%$ to 4.37 at $1.5 \%$, while soapnut-phosphate concentration decreases from 4.76 for $0.5 \%$ soapnut$50 \mathrm{mM}$ phosphate mixture to 4.64 for $1.5 \%$ soapnut$150 \mathrm{mM}$ phosphate mixture. SDS, however, became more alkaline, its $\mathrm{pH}$ being 9.45 at $10 \mathrm{mM}$ concentration and increasing to 10.08 at $30 \mathrm{mM}$ concentration. It leached out more $\mathrm{As}(\mathrm{V})$ at higher concentration due to the formation of higher number of micelles.

\section{Effect of soil:solution ratio}

Figure 4cI, cII show the results of arsenic desorption at five different extractant volumes $(\mathrm{ml})$ to soil mass $(\mathrm{g})$ ratios for contaminated soil sample and the change of $\mathrm{pH}$ after washing. For all the extractants, except phosphate, arsenic desorption increases with an increase in the soil:solution ratio. The percentage of arsenic desorption with $1 \%$ soapnut, $1 \%$ soapnut $-100 \mathrm{mM}$ phosphate and $20 \mathrm{mM}$ SDS solutions for 1:10 and 1:30 ratios are 54.62, 66.05; 63.44, 73.07 and $45.71,48.14$, respectively. In the case of $100 \mathrm{mM}$ phosphate solution, the desorption underwent slight reduction from $66.26 \%$ at $1: 10$ ratio to $63.97 \%$ at $1: 30$ ratio. With the exception of SDS, $\mathrm{pH}$ values of other extractants, after washing also undergo a little reduction with an increase in the soil:solution ratio. Although $\mathrm{pH}$ value of SDS becomes increasingly alkaline with increasing ratio, it experiences higher desorption due to enhanced micelle formation at higher volume. However, the decrease in performance of phosphate at higher volume could not be explained by $\mathrm{pH}$ of phosphate solution although published works on the $\mathrm{pH}$ dependence of $\mathrm{PO}^{4}-\mathrm{P}$ solubility in soils give a complex picture. Murrmann and Peech (1969) observed decreasing $\mathrm{PO}^{4}-\mathrm{P}$ solubility with increasing $\mathrm{pH}$ until about $\mathrm{pH}$ 5.5-6, where minimum solubility was obtained. Beyond $\mathrm{pH} 6, \mathrm{PO}^{4}-$ $P$ solubility increased until $8-9$, where it once again 

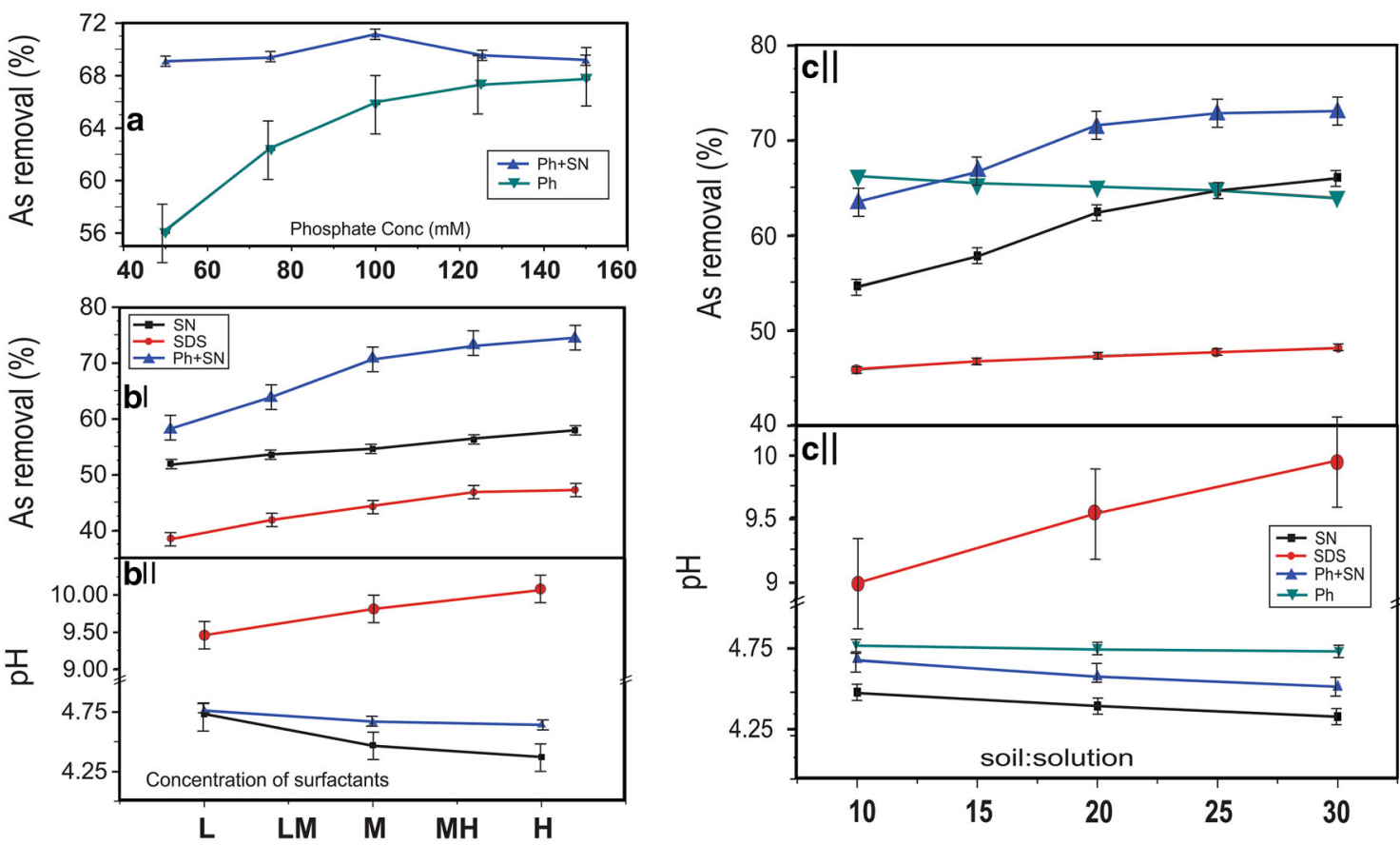

Fig. 4 a $\mathrm{As}(\mathrm{V})$ extractions by extractants of different phosphate strength (temperature: $20^{\circ} \mathrm{C}$, shaking time: $4 \mathrm{~h}$ ); (bI) As extraction by different concentrations of extractants (temperature: $20{ }^{\circ} \mathrm{C}$, shaking time: $4 \mathrm{~h})(b I I)$ change of $\mathrm{pH}$ of extractants with increasing surfactant concentration $\quad(\mathrm{L}-\mathrm{SDS}=10 \mathrm{mM}, \quad \mathrm{SN}=0.5 \%, \quad \mathrm{Ph}+\mathrm{SN}=$ $100 \mathrm{mM} \mathrm{Ph}+0.5 \% \quad \mathrm{SN} ; \quad$ LM-SDS $=15 \mathrm{mM}, \quad \mathrm{SN}=0.75 \%$, $\mathrm{Ph}+\mathrm{SN}=100 \mathrm{mM} \mathrm{Ph}+0.75 \% \mathrm{SN} ; \mathrm{M}-\mathrm{SDS}=20 \mathrm{mM}, \mathrm{SN}=$

decreased due to $\mathrm{Ca}-\mathrm{P}$ mineral precipitation. More recently, Devau et al. (2011) and Weng et al. (2011) presented similar results although for some soils, minimum $P$ solubility was found at even higher $\mathrm{pH}$ values $(>6)$. In the present case, the $\mathrm{pH}$ values of phosphate varied from 4.77 for 1:10 ratio to 4.73 for ratio of 1:30. A similar trend was obtained while performing the RSM experiments, as described in "Effect of soil:solution ratio" sub-section.

Optimization of soil washing process: Box-Behnken design

A polynomial regression equation was developed by using Box-Behnken design to analyze the factor interactions. Five replicates at the center point are used to determine the experimental error. The extent of $\mathrm{As}(\mathrm{V})$ desorption ranged from $48.84 \%$ to $79.56 \%$ (Özdemir et al. 2011).

Determination of the main and interaction effects of factors affecting the $\mathrm{As}(\mathrm{V})$ desorption process was done through ANOVA given in Table $4 \mathrm{~b}$. The model $F$ value is 47.33 , indicating that the model is significant for the range of experimental data obtained in this work. The $R^{2}$ value of second-order polynomial regression model is found to be

$1 \%, \quad \mathrm{Ph}+\mathrm{SN}=100 \mathrm{mM} \mathrm{Ph}+1 \% \quad \mathrm{SN} ; \quad \mathrm{MH}-\mathrm{SDS}=25 \mathrm{mM}$, $\mathrm{SN}=1.25 \%, \quad \mathrm{Ph}+\mathrm{SN}=100 \mathrm{mM} \mathrm{Ph}+1.25 \% \quad \mathrm{SN} ;$ $\mathrm{H}-\mathrm{SDS}=30 \mathrm{mM}, \mathrm{SN}=1.5 \%, \mathrm{Ph}+\mathrm{SN}=100 \mathrm{mM} \mathrm{Ph}+1.5 \%$ $\mathrm{SN})$. $\mathbf{c}$ Effect of soil:solution ratio on As extraction from contaminated soil $(c I)$ percentage of As extracted at different ratio; $(c I I)$ Final $\mathrm{pH}$ of the extracting liquid when added to soil (temperature: $20^{\circ} \mathrm{C}$, shaking time: $4 \mathrm{~h}$ )

0.956 (adj. 0.935). A normal probability plot of the residuals is used for checking the normality of the data, which is indicated when the points fall fairly close to the straight line, as shown in Fig. 5a (Antony 2003). Diagnostic plots of predicted versus actual values indicate the model adequacy, i.e., adequate agreement between real data and those obtained from the models (Fig. 5b). Visual examination shows that the data points fall approximately along a straight line. The AP values higher than four for all the responses confirm that all predicted models can be used to navigate the design space defined by the factorial design.

Considering the relative importance of estimated effects shown in the ANOVA table (Table 4b), the regression equation is simplified by neglecting the statistically insignificant effects. Values of "Prob $>$ F" less than 0.0500 indicate that the model terms are significant, while values greater than 0.1000 indicate that the model terms are insignificant. The final empirical model for $\mathrm{As}(\mathrm{V})$ desorption is described by the correlation in equation 8 , where the coefficients are given in Table 4a.

Arsenic Desorption $=66.56+6.77 * \mathrm{~A}+5.69 * \mathrm{~B}$

$$
+1.73 * \mathrm{C}-2.69 * \mathrm{AB}+5.84 * \mathrm{BC}
$$


Table 4 Box Behnken experimental design control factors, ANOVA and model validation

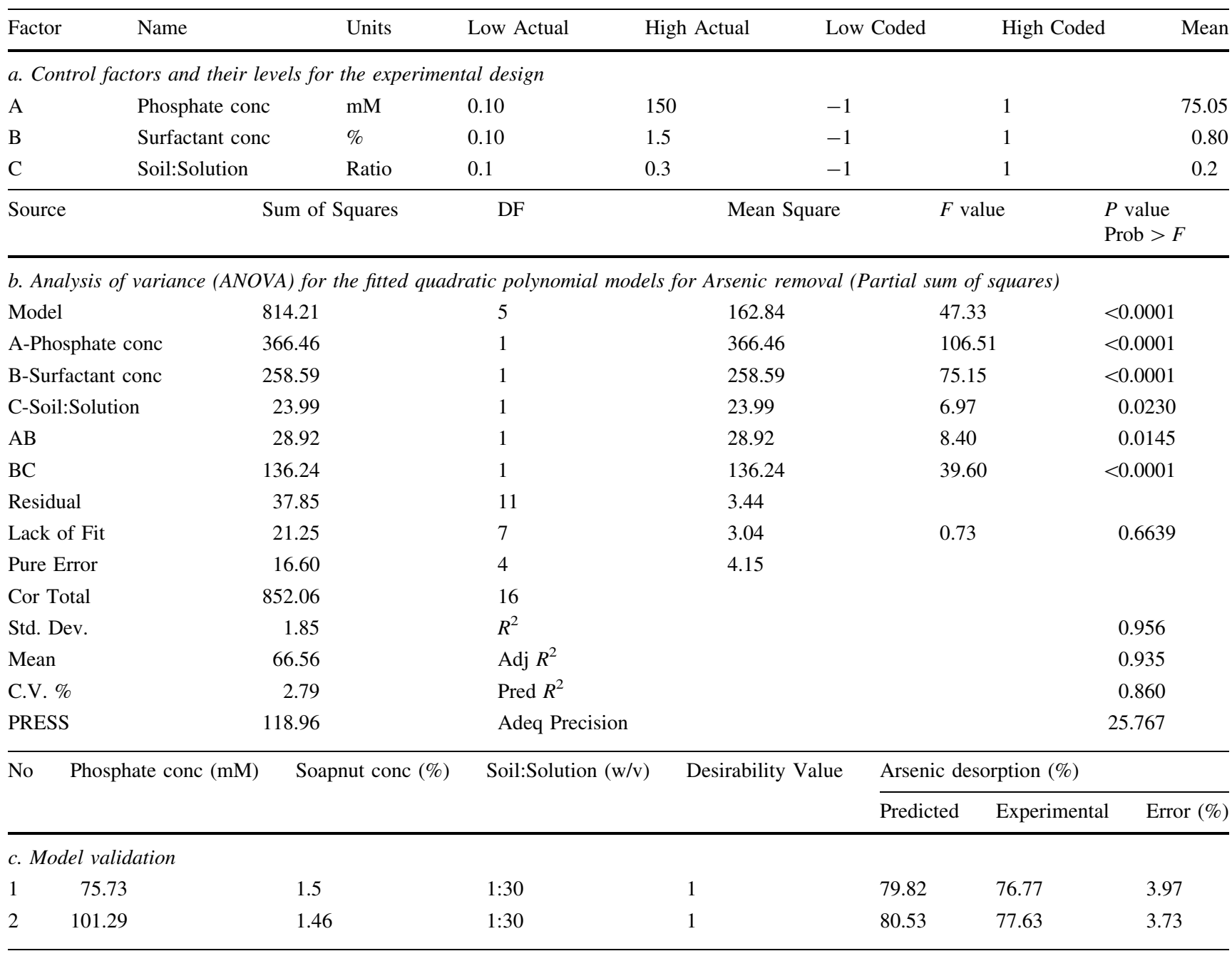

\section{Effects of process variables}

The Box-Behnken model is used to evaluate the effects of three important variables on $\mathrm{As}(\mathrm{V})$ desorption process. The best way to identify the relationship between the factors and the response is through the examination of surface plots as function of two factors by fixing the third factor at a certain level. In order to check the real importance of the factors on the $\operatorname{As}(\mathrm{V})$ desorption from soil, the obtained regression surfaces were plotted as function of process variables viz. phosphate concentration, surfactant concentration and soil:solution ratio.

Effect of phosphate concentration As evident from ANOVA results in Table $4 \mathrm{~b}$, phosphate concentration has the greatest influence on the desorption process of $\mathrm{As}(\mathrm{V})$ from soil. The relation between the phosphate concentration and As desorption is shown in Fig. 5cI, cIII as 3D graph, based on the fitted second-order polynomial equation (8). From the response surfaces, it can be observed that the phosphate concentrations have more direct interaction with surfactant concentration rather than with soil:solution ratio. As the concentration of the surfactant as well as the phosphate increases, the $\mathrm{As}(\mathrm{V})$ removal increases, as explained in Section Effect of phosphate concentration. High concentration of phosphate signifies large number of ions that can extract $\mathrm{As}(\mathrm{V})$ from $\mathrm{Al}$ and $\mathrm{Fe}$-bound fractions of soil, as observed by other researchers (Alam et al. 2001; Zeng et al. 2008). The maximum desorption efficiency was predicted to be $76 \%$ for the mixture of soapnut $(1.5 \%)$ and phosphate $(150 \mathrm{mM})$ in this work. However, the phosphate concentration and soil solution ratio has no such relationship. High phosphate concentration of $150 \mathrm{mM}$ works well at low soil:solution ratio of 0.10 , showing up to $75 \%$ desorption, while high phosphate concentration of $150 \mathrm{mM}$ at high soil:solution ratio of 0.30 shows desorption of up to $66 \%$ only. This is discussed in Section Effect of surfactant concentration. This inverse relation is also shown in Fig. 4bII. In order to establish the influence of phosphate concentration on $\mathrm{As}(\mathrm{V})$ removal from soil, batch experiments were 

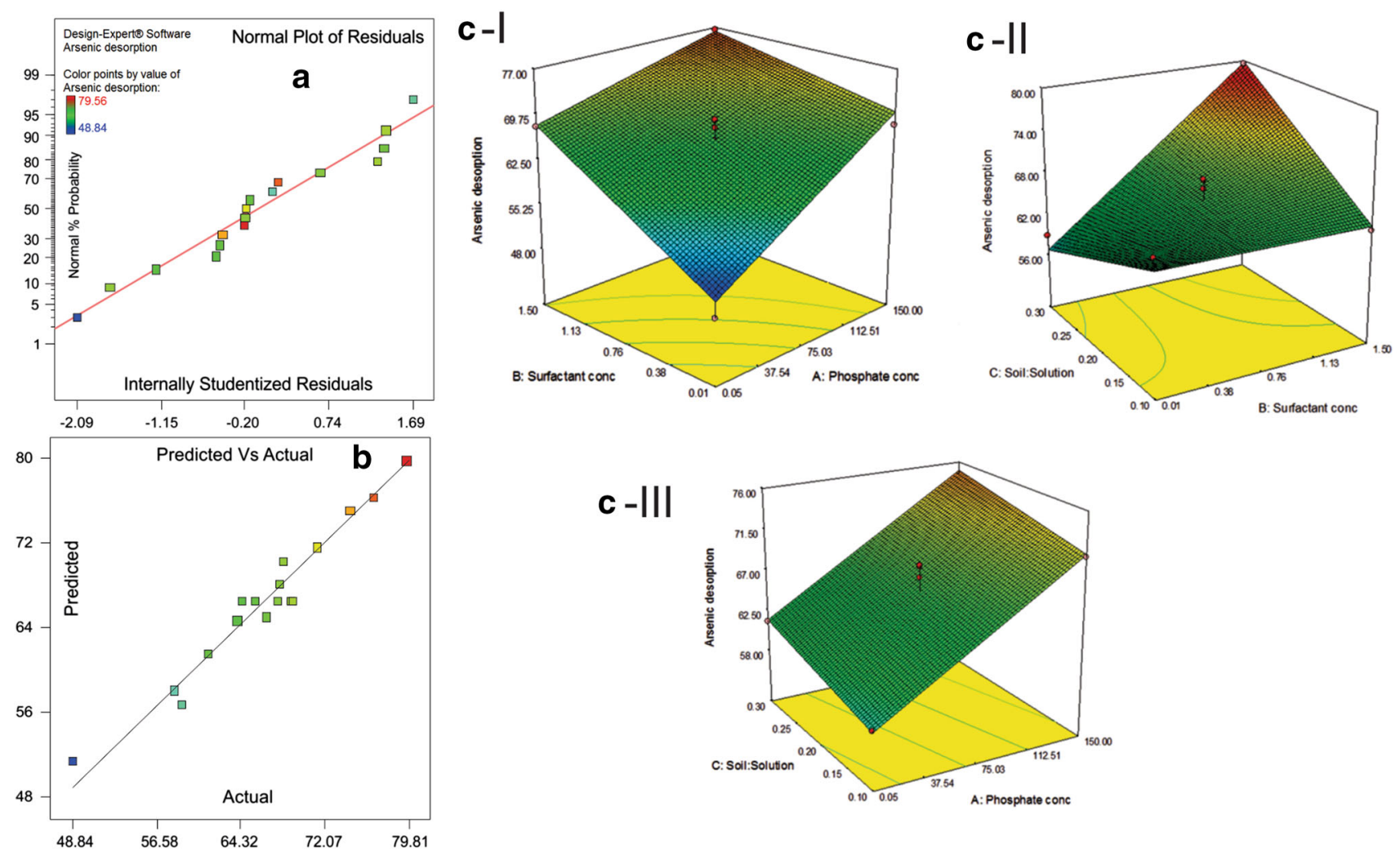

Fig. 5 a Normal probability plots of residuals for As removal; b predicted versus actual values plot for As removal c response surfaces for combined effect of $(c-I)$ surfactant and phosphate concentration at constant soil:solution ratio of $1: 20 ; \quad(c-I I)$

conducted, as explained in Section Effect of phosphate concentration.

Effect of surfactant concentration The experiments were conducted in the soapnut concentration ranges of $0.10 \%$ to $1.5 \%$. The lowest concentration is negligible in terms of concentration and was chosen to amplify the effect of phosphate in the absence of soapnut. The relation between soapnut concentration and $\mathrm{As}(\mathrm{V})$ desorption is shown in Fig. 5cI, cII. As observed earlier in the case of phosphate concentration, the $\operatorname{As}(\mathrm{V})$ desorption increases with an increase in the soapnut concentration for a constant soil solution ratio. Figure 5cI shows the graph at soil:solution ratio of 1:20. High concentration of soapnut signifies higher micellar concentration that can physically solubilize the $\mathrm{As}(\mathrm{V})$ from soil surface. However, the relationships among desorption rate, soapnut concentration and soil:solution ratio are not straight forward. At low soapnut concentration of $0.1 \%$ and low soil:solution ratio of $1: 10$, the $\mathrm{As}(\mathrm{V})$ desorption is around $65 \%$. It decreases to $64.85 \%$ when low soil:solution ratio of $1: 10$ and high soapnut concentration of $1.5 \%$ is used. Similarly, it decreases to $57.36 \%$ when minimum concentration of soapnut $(0.1 \%)$ is used at high soil:solution ratio of $1: 30$,

soil:solution ratio and surfactant concentration at constant phosphate concentration of $75.03 \mathrm{mM}$; and (c-III) soil:solution ratio and phosphate concentration at constant soapnut concentration of $0.76 \%$; on desorption of $\mathrm{As}(\mathrm{V})$ from soil

at fixed phosphate concentration of $75.03 \mathrm{mM}$. This result does not reciprocate when high soil:solution ratio and soapnut concentration are used and the desorption is around $80 \%$. The influence of this factor on soil washing process was demonstrated by batch experiments, as explained in "Effect of surfactant concentration" section.

Effect of soil:solution ratio $\mathrm{As}(\mathrm{V})$ desorption from soil was carried out at different soil:solution ratio ranging from 1:10 to $1: 30(\mathrm{w} / \mathrm{v})$. Figure $5 \mathrm{cII}$, cIII show the interaction of soil:solution ratio with surfactant and phosphate concentrations. The interaction with phosphate concentrations does not show any direct trend. For example, the lowest ratio of 1:10 and lowest soapnut concentration of $0.1 \%$ show a desorption of $65 \%$. The desorption value decreased to $56.77 \%$ at higher soil:solution ratio of 1:30, keeping soapnut concentration at its minimum $(0.1 \%)$ and a fixed phosphate concentration of $75.05 \mathrm{mM}$. Similar observations were made during the batch experiments as described in "Effect of soil:solution ratio" section. At the maximum value of soil:solution ratio of 1:30 and maximum value of soapnut concentration of $1.5 \%$, desorption is around $80 \%$ at constant phosphate concentration of $75.03 \mathrm{mM}$. At a fixed soapnut concentration of $0.80 \%$, the lowest phosphate 
concentration of $0.10 \mathrm{mM}$ as well as the lowest soil:solution ratio of 1:10, the desorption efficiency of $\mathrm{As}(\mathrm{V})$ was predicted as $58.06 \%$. With an increase in the soil:solution ratio to $1: 30$, the desorption efficiency would increase to $61.52 \%$. With an increase in soil:solution ratio to $1: 30$, highest phosphate concentration of $150 \mathrm{mM}$ results in a desorption of $75 \%$. In order to assess the influence of this factor on soil washing process, batch experiments were conducted, as elaborated in Section Effect of soil:solution ratio.

\section{Process optimization and model validation}

Optimization of $\operatorname{As}(\mathrm{V})$ desorption was performed by a multiple response method known as desirability function $(D)$. The goal of optimization was to maximize As $(\mathrm{V})$ removal performance by a combination of soapnut and phosphate solutions. Additional experiments were conducted under the suggested optimal conditions in three replicates in order to validate the model. Table $4 \mathrm{c}$ shows the best two processes for $\mathrm{As}(\mathrm{V})$ removal from contaminated soil. It can be concluded that the generated model was an adequate prediction of the $\mathrm{As}(\mathrm{V})$ desorption, with negligible errors.

Mechanism, fractionation and soil damage

\section{Zeta potential and FT-IR spectra}

The zeta potential values of the soil particles were measured in de-ionized water, $20 \mathrm{mM}$ SDS, $1 \%$ soapnut solution and $1 \%$ soapnut-100 mM phosphate solutions and were found to have values of $-34.3,-61.8,-11.8$ and $-11.3 \mathrm{mV}$, respectively. Therefore, for all the extractants, zeta potential values underwent significant changes. Compared with water, the zeta potential decreased significantly for $20 \mathrm{mM}$ SDS, indicating adsorption of the anionic surfactant SDS on the surface of soil particles. Ko et al. (1998) (Ko et al. 1998) also observed a decrease in value of zeta potential of kaolinite when it sorbed SDS on its existing negative basal plane, as the negatively charged kaolinite particles adsorbed SDS head groups. However, the zeta potential values are much higher for soapnut and soapnut-phosphate mixture due to the nonionic tails of saponin molecules which were adsorbed on the soil particles, thereby reflecting higher zeta potential values. Raatz and Härtel (1996) (Raatz and Härtel 1996) postulated that surfactant adsorption is essential for removal of soil contaminants, and surfactants that adsorb on the soil-water interphases are more effective detergents. Therefore, both soapnut and SDS were adsorbed on soil particles and were effective detergents.

FT-IR spectral data, as exhibited in Fig. 6a, displayed the differences in average absorbance spectra for the soapnut and soapnut-phosphate solutions, both with and without $\mathrm{As}(\mathrm{V})$, together with the absorption range of different molecular vibrations present in phenolic-OH at $3,435 \mathrm{~cm}^{-1}$, carbonyl groups of carboxylic acid at $2,090 \mathrm{~cm}^{-1}$ and alkene groups at $1,640 \mathrm{~cm}^{-1}$. These are similar to the observations made by Pradhan and Bhargava (2008) (Pradhan and Bhargava 2008). All the spectra resembled that of only soapnut and no shifting of peaks in FT-IR spectra was observed in the soapnut solution in presence of phosphate and $\mathrm{As}(\mathrm{V})$. Therefore, it can be suggested that neither chemical interaction was involved when phosphate was mixed with soapnut, nor in the As removal mechanism by the extractant solutions. Similar analysis in UV-visible frequency range also did not show any shift in the peaks, hence not presented.

\section{Fractionation of $A s(V)$ in soil}

According to Mulligan et al. (2001a) (Mulligan et al. 2001a), the purpose of sequential extraction studies are to determine the fraction from which the pollutant is being removed. This information can be used to assess the effectiveness of a particular extractant. However, contaminants retained in the residual fractions are very difficult to remove. Fe(III) is the most effective cation in binding $\mathrm{As}(\mathrm{V})$ both in groundwater and soil (Chowdhury et al. 1999; Tokunaga and Hakuta 2002; Wasay et al. 2000). As(V) in the soil before and after desorption was fractionated by the sequential extraction procedure established by Halls et al. (1996). The results are as shown in Fig. 6b. In the original arsenic-contaminated soil, $\operatorname{As}(\mathrm{V})$ was retained mainly in amphoteric ferric oxyhydroxide (Am-Fe-ox), adsorbed-exchangeable-carbonate (AEC) fraction and crystalline Fe-oxide (Cry-Fe-ox) fractions. However, sulphide and organic fractions and residual fractions had very little amount of $\mathrm{As}(\mathrm{V})$. The AEC fraction was the easiest to remove, and all the extractants removed almost all of the $\mathrm{As}(\mathrm{V})$ in this fraction. Through the SDS treatment, $47.43 \%$ of $\mathrm{As}(\mathrm{V})$ was extracted, and the remaining arsenic in the soil was fractionated into $43.87 \% \mathrm{Am}-\mathrm{Fe}-\mathrm{ox}$ form and $6.47 \%$ in Cry-Fe-ox form. AEC part was totally removed. After soapnut treatment, $31.36 \%$ As remained in Am-Fe-ox form and $4.36 \%$ in Cry-Fe-ox form. The corresponding values of Am-Fe-ox form, Cry-Fe-ox form phosphate and soapnut-phosphate mixtures are $28.07 \%, 3.75 \%$ and $22.84 \%, 3.65 \%$, respectively. This indicates that the extractants that can progressively remove $\mathrm{As}(\mathrm{V})$ from Am-Fe-ox states are in the order $\mathrm{SDS}<$ soapnut $<$ phosphate $<$ soapnut-phosphate. Therefore, soapnut-phosphate mixture was able to extract the highest amount of $\mathrm{As}(\mathrm{V})$ from the Am-Fe-oxide hydroxides and ultimately was the best extractant, as shown in Fig. 2 . Negligible amount of $\mathrm{As}(\mathrm{V})$ was retained in the residual 

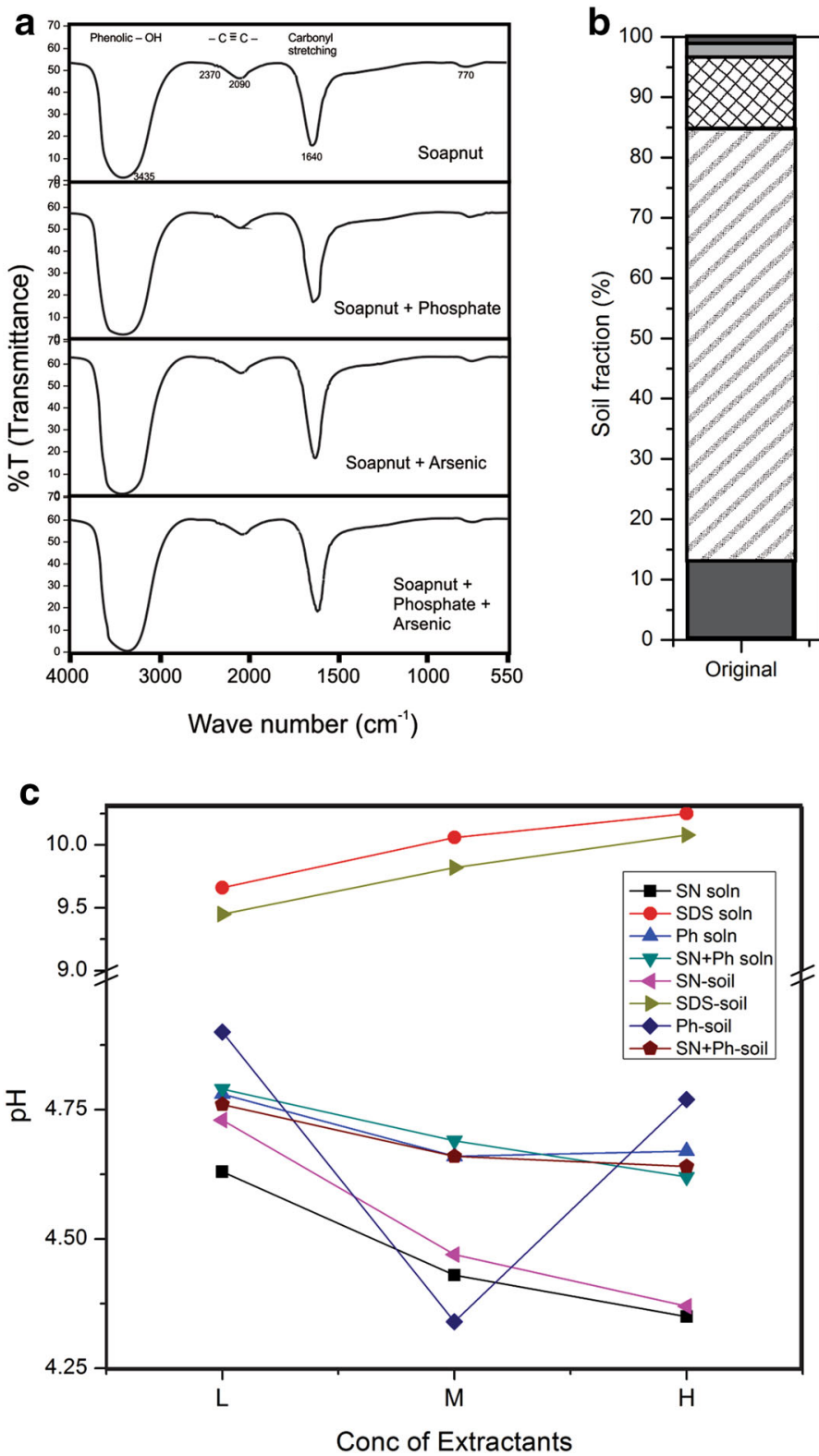
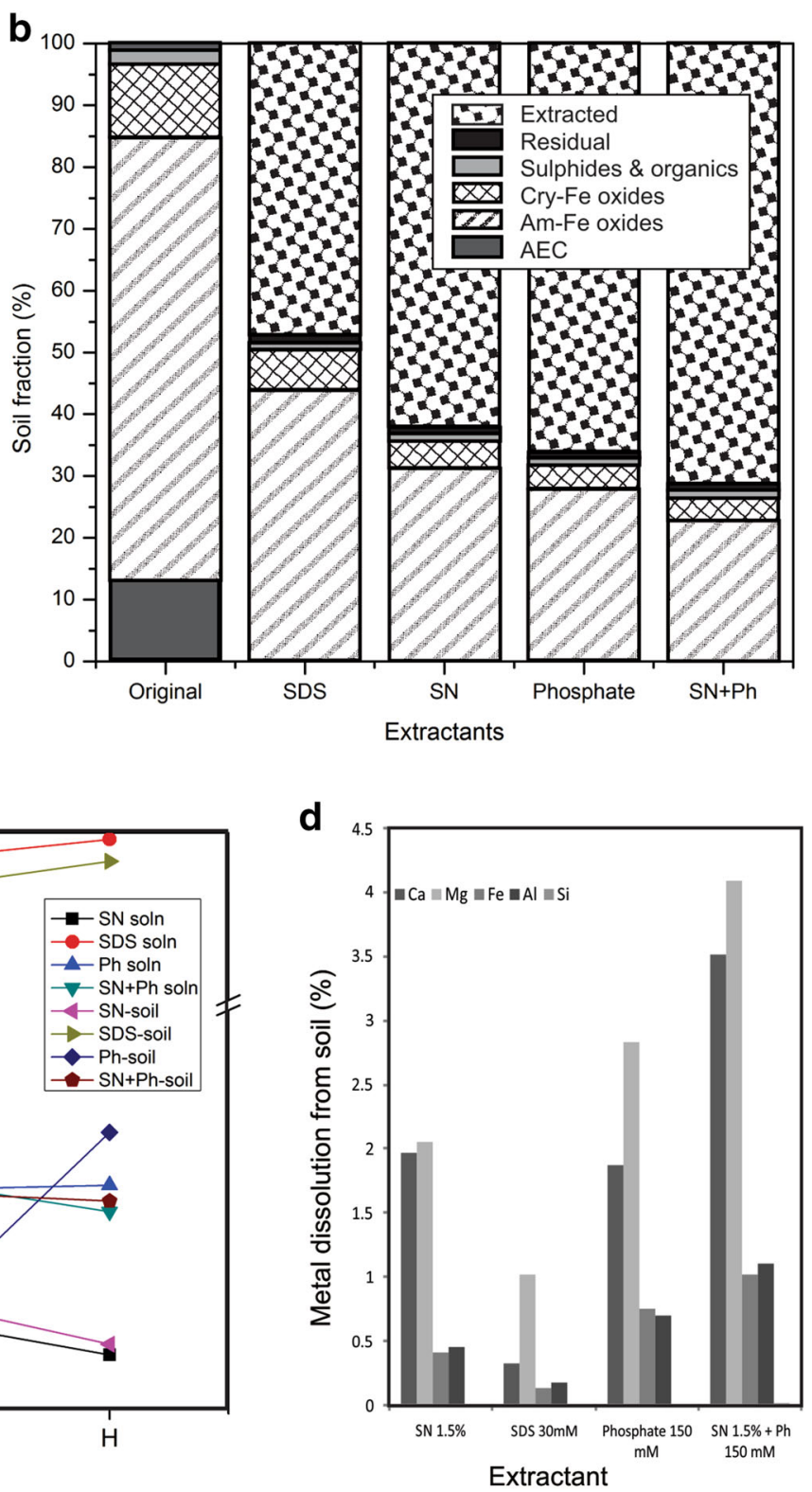

Fig. 6 a FT-IR spectra of influent and effluent soapnut solutions b Sequential extraction of As(V) following (Hall et al. 1996), c Change in pH of soil during washing process, $\mathbf{d}$ Metal dissolution from washed soil (\%)

fraction, signifying high effectiveness of the soil washing procedure by phosphate and soapnut.

\section{Damage to soil}

Figure $6 \mathrm{c}$ shows the $\mathrm{pH}$ of soapnut, phosphate and soapnut-phosphate mixtures at different concentrations and the changes of soil $\mathrm{pH}$ after using these extractants. For extractants without soil, with increase in concentrations, $\mathrm{pH}$ of $\mathrm{KH}_{2} \mathrm{PO}_{4}$ solutions decreased by up to 0.2 unit, $\mathrm{pH}$ of soapnut solutions decreased by up to 0.3 unit and $\mathrm{pH}$ of soapnut-phosphate mixture decreased by up to 0.2 unit. All these three varied within a range of 4.35 to 4.79 . However, in case of SDS solution, it was highly alkaline and the $\mathrm{pH}$ were $9.66,10.06$ and 10.25 for concentrations of $10 \mathrm{mM}$, $20 \mathrm{mM}$ and $30 \mathrm{mM}$, respectively. After the soil washing, $\mathrm{pH}$ of wash liquid was measured once again. The solutions were found to attain slightly higher $\mathrm{pH}$ for the three acidic extractants, and the range was between 4.37 to 4.90 . For SDS solution, it attained lower $\mathrm{pH}$ of values 9.45, 9.82, 10.08 for $10 \mathrm{mM}, 20 \mathrm{mM}$ and $30 \mathrm{mM}$, respectively. Therefore, the overall trend shows a tendency to shift the 
$\mathrm{pH}$ toward neutrality, given that the soil $\mathrm{pH}$ is 6.60 . Dissolution of soil mineral components such as $\mathrm{Ca}, \mathrm{Mg}, \mathrm{Al}, \mathrm{Si}$ and $\mathrm{Fe}$ was evaluated (Fig. 6d). High concentrations of the extractants were used because Zeng et al. (2008) found that higher the concentration of the extractants, higher is the degradation of soil. In this case, no considerable degradation was found in the soil structure. With $1.5 \%$ soapnut$150 \mathrm{mM}$ phosphate solution, $3.51 \% \mathrm{Ca}, 4.09 \mathrm{Mg}$ and $1.02 \% \mathrm{Fe}$ leached out. Other extractants dissolute still lower percentage of these metals, indicating negligible chemical withering. High amounts of $\mathrm{Mg}, \mathrm{Ca}$ and $\mathrm{Fe}$ were present in the soil as observed from the XRD spectra (Fig. 1a). Consequently, their percentage in the extractants was higher than $\mathrm{Al}$ and $\mathrm{Si}$, and they were bound more strongly as a part of the mineral structure of the soil. Among the soil components, $\mathrm{Ca}, \mathrm{Fe}$, and $\mathrm{Al}$ contribute to sorption of As by soils, whereas $\mathrm{Si}$ and other components do not (Alam et al. 2001; Wasay et al. 2000). Soapnutphosphate mixture resulted in more $\mathrm{Ca}$ and $\mathrm{Fe}$ dissolution than others and concurrently was found to remove most $\operatorname{As}(\mathrm{V})$. This is illustrated in Fig. 2.

\section{Conclusion}

Laboratory batch experiments have been conducted for studying removal of $\mathrm{As}(\mathrm{V})$ from high iron content soil by soapnut and phosphate solutions. The results indicate that the efficiency of soapnut and phosphate are almost similar while soapnut-phosphate mixture has a higher efficiency. While effectiveness of soapnut is imparted by the formation of micelle and solubilization of arsenic from the surface of the soil particles, phosphate replaced arsenate from soil due to their structural and chemical similarities (phosphate: $\mathrm{p} K_{1}=2.1, \mathrm{p} K_{2}=7.2, \mathrm{p} K_{3}=12.3$; arsenate: $\left.\mathrm{p} K_{1}=2.2, \mathrm{p} K_{2}=6.97, \mathrm{p} K_{3}=11.53\right)$ and is always found to be an advantage during competitive adsorption (Manning and Goldberg 1996; Hingston et al. 1971). SDS, an anionic surfactant, has alkaline $\mathrm{pH}$ and is not as effective. The kinetic study reveals that desorption equilibrium can be practically obtained within $4 \mathrm{~h}$ of operation and the Elovich model best represents the $\mathrm{As}(\mathrm{V})$ desorption kinetics among the four models used in this study. Sequential extraction shows that arsenic is retained by the soil mainly in Am-Fe-oxide form, and soapnut-phosphate mixture is most successful in extracting As from this fraction. The arsenic desorption efficiency can be increased by increasing soil:solution ratio, surfactant and phosphate concentration. However, 1:20 ratio is found to be the best for phosphate solution. Box-Behnken design predicts up to $80 \% \mathrm{As}(\mathrm{V})$ removal by using a mixture of $1.46 \%$ soapnut-101.29 mM phosphate in 1:30 ratio. Although soil $\mathrm{pH}$ decreases while using all of these extractants, no significant dissolution of soil components $(\mathrm{Ca}, \mathrm{Mg}, \mathrm{Si})$ is observed, indicating all three of them are environment friendly soil washing agents. Since the presence of phosphate in soapnut boosts the later's performance from 62 to $71 \%$ (Fig. 2), it can be expected that soapnut will be effective in washing out arsenic from aquifer and agricultural fields having high residues of phosphate fertilizer. Finally, it can be stated that while material cost for washing 1 ton of soil by $1 \%$ soapnut will be USD 28.57 , washing by $20 \mathrm{mM}$ SDS solution will cost about USD 27.7, going by the present market rate. Material handling, structural installation and operational cost being similar, both the natural and synthetic surfactants have comparable cost factors, with the added advantage of environmentally safe and biodegradability in favor of soapnut. Soapnut can be investigated for removal of heavy metals such as $\mathrm{Cd}, \mathrm{Zn}$ and $\mathrm{Cr}$ from soil.

Acknowledgments The authors acknowledge the funding provided by University of Malaya, Kuala Lumpur (Grant nos: PV102-2011A and UM-QUB6A-2011) for carrying out this research.

\section{References}

Alam MGM, Tokunaga S, Maekawa T (2001) Extraction of arsenic in a synthetic arsenic-contaminated soil using phosphate. Chemosphere 43(8):1035-1041. doi:10.1016/s0045-6535(00)00205-8

Antony J (2003) Design of experiments for engineers and scientists. Butterworth-Heinemann, New York

Chapman HD (1965) Cation-exchange capacity, vol 9. Methods of soil analysis: chemical and microbiological properties. Agronomy

Chappell J, Chiswell B, Olszowy H (1995) Speciation of arsenic in a contaminated soil by solvent extraction. Talanta 42(3):323-329. doi:10.1016/0039-9140(95)01395-r

Chen W-J, Hsiao L-C, Chen KK-Y (2008) Metal desorption from copper(II)/nickel(II)-spiked kaolin as a soil component using plant-derived saponin biosurfactant. Process Biochem 43(5):488-498. doi:10.1016/j.procbio.2007.11.017

Cheng H, Hu Y, Luo J, Xu B, Zhao J (2009) Geochemical processes controlling fate and transport of arsenic in acid mine drainage (AMD) and natural systems. J Hazard Mater 165(1-3):13-26. doi:10.1016/j.jhazmat.2008.10.070

Chien SH, Clayton WR (1980) Application of Elovich equation to the kinetics of phosphate release and sorption in soils. Soil Sci Soc Am J 44:265-268

Chowdhury SR, Yanful EK (2010) Arsenic and chromium removal by mixed magnetite-maghemite nanoparticles and the effect of phosphate on removal. J Environ Manage 91(11):2238-2247. doi:10.1016/j.jenvman.2010.06.003

Chowdhury TR, Basu GK, Mandal BK, Biswas BK, Samanta G, Chowdhury UK, Chanda CR, Lodh D, Roy SL, Saha KC, Roy S, Kabir S, Quamruzzaman Q, Chakraborti D (1999) Arsenic poisoning in the Ganges delta. Nature 401(6753):545-546

Craw D (2005) Potential anthropogenic mobilisation of mercury and arsenic from soils on mineralised rocks, Northland. N.Z. J Environ Manag 74(3):283-292. doi:10.1016/j.jenvman.2004. 10.005 
Devau N, Hinsinger P, Le Cadre E, Colomb B, Gérard F (2011) Fertilization and $\mathrm{pH}$ effects on processes and mechanisms controlling dissolved inorganic phosphorus in soils. Geochim Cosmochim Acta 75(10):2980-2996

Dobran S, Zagury GJ (2006) Arsenic speciation and mobilization in CCA-contaminated soils: Influence of organic matter content. Sci Total Environ 364(1-3):239-250

Hall GEM, Vaive JE, Beer R, Hoashi M (1996) Selective leaches revisited, with emphasis on the amorphous $\mathrm{Fe}$ oxyhydroxide phase extraction. J Geochem Explor 56(1):59-78. doi:10.1016/ 0375-6742(95)00050-x

Havlin JL, Westfall DG, Olsen RS (1985) Mathematical models for potassium release kinetics in calcareous soils. Soil Sci Soc Am J 49:366-370

Hingston FJ, Posner AM, Quirk JP (1971) Competitive adsorption of negatively charged ligands on oxide surfaces. Discuss Faraday Soc 52:334-342

Jacobs LW, Syers JK, Keeney DR (1970) Arsenic sorption by soils. Soil Sci Soc Am J 34(5):750-754. doi:10.2136/sssaj1970. $03615995003400050024 x$

Jain CK, Ali I (2000) Arsenic: occurrence, toxicity and speciation techniques. Water Res 34(17):4304-4312. doi:10.1016/s00431354(00)00182-2

Jang M, Hwang JS, Choi SI, Park JK (2005) Remediation of arseniccontaminated soils and washing effluents. Chemosphere 60(3):344-354. doi:10.1016/j.chemosphere.2004.12.018

Jomova K, Jenisova Z, Feszterova M, Baros S, Liska J, Hudecova D, Rhodes CJ, Valko M (2011) Arsenic: toxicity, oxidative stress and human disease. J Appl Toxicol 31(2):95-107. doi:10.1002/ jat. 1649

Ko S-O, Schlautman MA, Carraway ER (1998) Effects of solution chemistry on the partitioning of phenanthrene to sorbed surfactants. Environ Sci Technol 32:3542-3548

Kommalapati RR, Roy D (1996) Bioenhancement of soil microorganisms in natural surfactant solutions: I. Aerobic. J Environ Sci Health Part A 31:1951-1964

Kommalapati RR, Valsaraj KT, Constant WD, Roy D (1997) Aqueous solubility enhancement and desorption of hexachlorobenzene from soil using a plant-based surfactant. Water Res 31(9):2161-2170

Lee CS, Kao MM (2004) Effects of extracting reagents and metal speciation on the removal of heavy metal contaminated soils by chemical extraction. J Environ Sci Health Part A 39(5): 1233-1249

Li D, Huang S, Wang W, Peng A (2001) Study on the kinetics of cerium(III) adsorption-desorption on different soils of China. Chemosphere 44(4):663-669

Lu P, Zhu C (2011) Arsenic Eh-pH diagrams at $25^{\circ} \mathrm{C}$ and 1 bar. Environ Earth Sci 62(8):1673-1683. doi:10.1007/s12665-010-0652-x

Manning BA, Goldberg S (1996) Modeling competitive adsorption of arsenate with phosphate and molybdate on oxide minerals. Soil Sci Soc Am J 60(1):121-131

Mihaljevič M, Poňavič M, Ettler V, Šebek O (2003) A comparison of sequential extraction techniques for determining arsenic fractionation in synthetic mineral mixtures. Anal Bioanal Chem 377(4):723-729

Mulligan CN (2005) Environmental applications for biosurfactants. Environ Pollut 133(2):183-198

Mulligan CN, Wang S (2006) Remediation of a heavy metalcontaminated soil by a rhamnolipid foam. Eng Geol $85(1-2)$ : $75-81$

Mulligan CN, Yong RN, Gibbs BF (1999) On the use of biosurfactants for the removal of heavy metals from oil-contaminated soil. Environ Prog 18(1):50-54

Mulligan CN, Yong RN, Gibbs BF (2001a) Heavy metal removal from sediments by biosurfactants. J Hazard Mater 85(1-2):111-125
Mulligan CN, Yong RN, Gibbs BF (2001b) Remediation technologies for metal-contaminated soils and groundwater: an evaluation. Eng Geol 60(1-4):193-207

Murrmann RP, Peech M (1969) Effect of $\mathrm{pH}$ on labile and soluble phosphate in soils1. Soil Sci Soc Am J 33(2):205-210. doi:10. 2136/sssaj1969.03615995003300020015x

Oorts K, Ghesquiere U, Smolders E (2007) Leaching and aging decrease nickel toxicity to soil microbial processes in soils freshly spiked with nickel chloride. Environ Toxicol Chem 26(6):1130-1138. doi:10.1897/06-533r.1

Özdemir E, Duranoğlu D, Beker Ü, Avc1 AÖ (2011) Process optimization for $\mathrm{Cr}(\mathrm{VI})$ adsorption onto activated carbons by experimental design. Chem Eng J 172(1):207-218. doi:10.1016/ j.cej.2011.05.091

Pradhan M, Bhargava P (2008) Defect and microstructural evolution during drying of soapnut-based alumina foams. J Eur Ceram Soc 28(16):3049-3057

Raatz S, Härtel G (1996) Application of surfactant combinations for cleaning clays contaminated with polycyclic aromatic hydrocarbons. Anwendung von tensidkombinationen zur reinigung PAKkontaminierter tone 37(2):57-62

Roy D, Kommalapati RR, Valsaraj KT, Constant WD (1995) Soil flushing of residual transmission fluid: application of colloidal gas aphron suspensions and conventional surfactant solutions. Water Res 29(2):589-595

Roy D, Kommalapati RR, Mandava S, Valsaraj KT, Constant WD (1997) Soil washing potential of a natural surfactant. Environ Sci Technol 31(3):670-675

Saxena D, Pal R, Dwivedi AK, Singh S (2004) Characterization of sapindosides in Sapindus mukorossi saponin (reetha saponin) and quantitative determination of sapindoside B. J Sci Ind Res 63:181-186

Smedley PL, Kinniburgh DG (2002) A review of the source, behaviour and distribution of arsenic in natural waters. Appl Geochem 17:517-568

Song S, Zhu L, Zhou W (2008) Simultaneous removal of phenanthrene and cadmium from contaminated soils by saponin, a plant-derived biosurfactant. Environ Pollut 156(3):1368-1370. doi:10.1016/j.envpol.2008.06.018

Sparks DL, Zelazny LW, Martens DC (1980a) Kinetics of potassium desorption in soil using miscible displacement. Soil Sci Soc Am J 44:1205-1208

Sparks DL, Zelazny LW, Martens DC (1980b) Kinetics of potassium exchange in a paleudult from the coastal plain of Virginia. Soil Sci Soc Am J 44:37-40

Storer DA (1984) A simple high sample volume ashing procedure for determining soil organic matter. Commun Soil Sci Plant Anal 15:759-772

Suhagia BN, Rathod IS, Sindhu S (2011) Sapindus mukorossi (Areetha): an overview. Int J Pharm Sci Res 2(8):1905-1913

Sundstrom DW, Weir BA, Klei HE (1989) Destruction of aromatic pollutants by UV light catalyzed oxidation with hydrogen peroxide. Environ Prog 8(1):6-11. doi:10.1002/ep. 3300080107

Tokunaga S, Hakuta T (2002) Acid washing and stabilization of an artificial arsenic-contaminated soil. Chemosphere 46(1):31-38. doi:10.1016/s0045-6535(01)00094-7

Wang S, Mulligan CN (2009) Arsenic mobilization from mine tailings in the presence of a biosurfactant. Appl Geochem 24(5):928-935. doi:10.1016/j.apgeochem.2009.02.017

Wang S, Zhao X (2009) On the potential of biological treatment for arsenic contaminated soils and groundwater. J Environ Manag 90(8):2367-2376. doi:10.1016/j.jenvman.2009.02.001

Wasay SA, Haron MJ, Tokunaga S (1996) Adsorption of fluoride, phosphate, and arsenate ions on lanthanum-impregnated silica gel. Water Environ Res 68(3):295-300 
Wasay SA, Parker W, Van Geel PJ, Barrington S, Tokunaga S (2000) Arsenic pollution of a loam soil: retention form and decontamination. Soil Sediment Contam 9(1):51-64

Weng H, Liu Y, Chen H (1997) Environmental geochemical features of arsenic in soil in China. J Environ Sci (China) 9(4):385-395

Weng L, Vega FA, Van Riemsdijk WH (2011) Competitive and synergistic effects in $\mathrm{pH}$ dependent phosphate adsorption in soils: LCD modeling. Environ Sci Technol 45(19):8420-8428
Yamaguchi N, Nakamura T, Dong D, Takahashi Y, Amachi S, Makino T (2011) Arsenic release from flooded paddy soils is influenced by speciation, $\mathrm{Eh}, \mathrm{pH}$, and iron dissolution. Chemosphere 83(7):925-932. doi:10.1016/j.chemosphere.2011.02.044

Zeng M, Liao B, Lei M, Zhang Y, Zeng Q, Ouyang B (2008) Arsenic removal from contaminated soil using phosphoric acid and phosphate. J Environ Sci (China) 20(1):75-79. doi:10.1016/ s1001-0742(08)60011-x 